\title{
Analysis of the Quantity and Average Age of Copper in-Use Stock in the U.S. from 1985 to 2014
}

\author{
Minxi Wang, Yanan Liang, Wu Chen and Xin Li * \\ College of Management Science, Chengdu University of Technology, Chengdu 610051, China; \\ wangminxi@mail.cdut.edu.cn (M.W.); yananliang45@sina.com (Y.L.); chenwu92@yeah.net (W.C.) \\ * Correspondence: lixin2012@cdut.cn; Tel.: +86-136-834-08672
}

\begin{abstract}
With the increasing of copper consumption, the in-use stock of copper tends to increase. This paper used the "average use life method" to quantify the amount of copper in-use stock, and calculated the average age of in-use stock. It was indicated that the total in-use stock had an overall smooth trends, and reached its peak in 2007 was about $68.9 \mathrm{Mt}$ (million tons), in addition, in-use stock per capita reached its peak, $234 \mathrm{~kg} / \mathrm{capita}$ in 2001. The results demonstrated that during the period 1992-2002, the average age of copper in-use stock was continually decreased, but gradually increased since the year 2003. The fixed assets depreciation method used in this paper is applied to analyze depreciated copper in-use stock, and to analyze the relationship with economic indicator (GDP). It was demonstrated that it was inconsistent with the theory of Environmental Kuznets Curve (EKC) before 2000, this might be the demand for copper in the service sector is greater than the reduced strength of alternatives. Finally, scenario analysis of future copper in-use stock and depreciated copper in-use stock per capita in the U.S. were presented. The corresponding average age of the in-use stock will have a slight rise in the next decade.
\end{abstract}

Keywords: copper; in-use stock; average age; average use life method; fixed assets depreciation method

\section{Introduction}

Industrialization and urbanization are moving natural resources at a growing pace from the lithosphere to anthropogenic stocks of products in use [1]. Material flows are the link between stocks and processes [2]. Efficient recovery of these stocks can decrease reliance on primary metals. It can better achieve the sustainable development of resources in the absence of natural resources. As a kind of potential resources, we should know where the metals are used, stocked, and lost through their life cycle in society, and require to estimate how much of in-use stocks might be recovered. In-use stock data are used to examine an aspect of a commodity's availability. It also highlights the need of integrated management of primary and secondary resources. After iron and aluminum, copper ranks the third in the world in terms of production and consumption of metal. It covers widely diverse applications including building and construction, infrastructure, industrial equipment, transport, and other products. With the increasing consumption, the in-use stock of copper tends to increase. A well-known concept for flow analysis is material flow accounting (MFA) that aims at assessing total mass flows of a society [3]. It is also a common analytical tool to characterize material stocks and flows within national, regional, and global boundaries [4,5]. It is systematic assessment of materials within a system defined in space and time [6]. That is to say, MFA gives information of a material mass flow into defined boundaries. While MFA may address composite flows of numerous materials, the term substance flow analysis (SFA) is utilized when referring to specific substance such as copper [7]. In fact, different works have already been conducted on the implementation of SFA to help facing problematic of metals management, especially in the framework of the stocks and flows (STAF) project initiated by the Center for Industrial Ecology at Yale University.

Quantifying the amount of in-use stock can provide an estimate about growth trajectories and future demand based on material intensities that are representative of specific standards of living 
[8]. Many literatures have been reported about metals' in-use stocks to date. The "stocks and flows" model was used to analyze the in-use stock for copper and zinc of the Europe in 1994 [9,10]. A multi-regional material flow analysis (MFA) model was used to estimate the in-use stock of copper for 200 countries in the year 2000 [11]. Besides copper, both top-down and bottom-up approach adopted to analyze steel in-use stock of Japan in 2009 [12], the aluminum in-use stock in the U.S. was calculated and made a description about the relationship between in-use stock and GDP [13], after this, in the year 2013, the global aluminum in-use stock in geological reserve and anthropogenic reservoir from 1990 to 2010 on a country level through a dynamic material flow model [14]. Understanding the in-use stock of metals has attracted growing interest in recent years, it not only provided ultimate demand for services in our societies, but also can help to better benchmark future scenarios. These studies, however, focus on a specific country and a specific year, previous estimates of in-use stocks of metals have revealed the potential availability, but few studies have been carried out copper average age of in-use stock, considered the depreciation of copper and related the in-use stock to economic indicator. The "average age method" was applied to analyze the social stock, and average age for aluminum and copper [15], steel [16] in China. This paper gave a perspective for further analysis of the per-capita copper stock in use and the GDP of the U.S, as well as the relationship between them.

\section{Materials and Methods}

\subsection{Definition and description of copper stocks}

Copper is used in a wide range of applications (electricity, electronic equipment, building, chemistry, etc.), it is expensive and pure copper is infinitely recyclable at $100 \%$ without any property losses [17]. Copper's lifecycle includes five stages: extraction from virgin ores, production of copper containing products, consumption, accumulation in social stock and scrap recycling. In fact, the copper lifecycle is complicated. The material cycle model for copper is based on the principle of mass balance. Consumption is the quantity of refined copper used by the domestic industry (brass mills, wire-rod mills, foundries, etc.), as measured by direct survey of the copper consuming industries, in the production of semi-fabricates, castings, chemicals, etc. in the United States. In this paper, we simplified the consumption between the year $(t-\Delta t)$ and $t$, constituting the in-use stock in the year $t$. The copper products will be discarded from in-use stock and reclaimed as secondary resources after is lifetime. The average service life of copper products is assumed to be 30 years [4]. The data imports (or exports) are the amounts of refined copper imported (or exported) into (from) the United States in various shapes and forms, import data exclude all semi-fabricated and manufactured copper products, primary production means the copper produced from ore, concentrate, or precipitate; secondary production is the copper recovered from old scrap. This paper aimed to quantify the in-use stock of copper in the U.S. during the period 1985-2014, and combined the population, gross domestic product (GDP), and the average age of in-use stock are also calculated.

The scope of this paper is to analyze the in-use stock of copper in the United States. The space scope is obviously the United States. In fact, given that the decisions are taken at a country level, SFA is applied at this level. Although the time boundary is based on 1985-2014, actually a mass of data from 1925 to 2014 was analyzed.

For different kinds of copper contained products, which are flowed into in-use stock and then lowed out of in-use stock in a period of their lifetime [6]. Generally, metal flowed into in-use and the outflow as discarded products can be got by functions of time. In-use stock at a random time $t$ can be calculated by: 
where $\mathrm{M}_{\mathrm{in}}(t)$ is the inflow to in-use stock, Mout $(t)$ is the discarded flowed out of in-use stock; $t_{0}$ represents the time of the initial time step, $t$ is the current time step, and $S\left(t_{0}\right)$ represents the extant stock at the initial time step.

It is easy to understand that in the socioeconomic system, the in-use stock will change over time. The in-use stage likes a reservoir, because it is storage locations for copper. The process can be simplified as Figure 1:

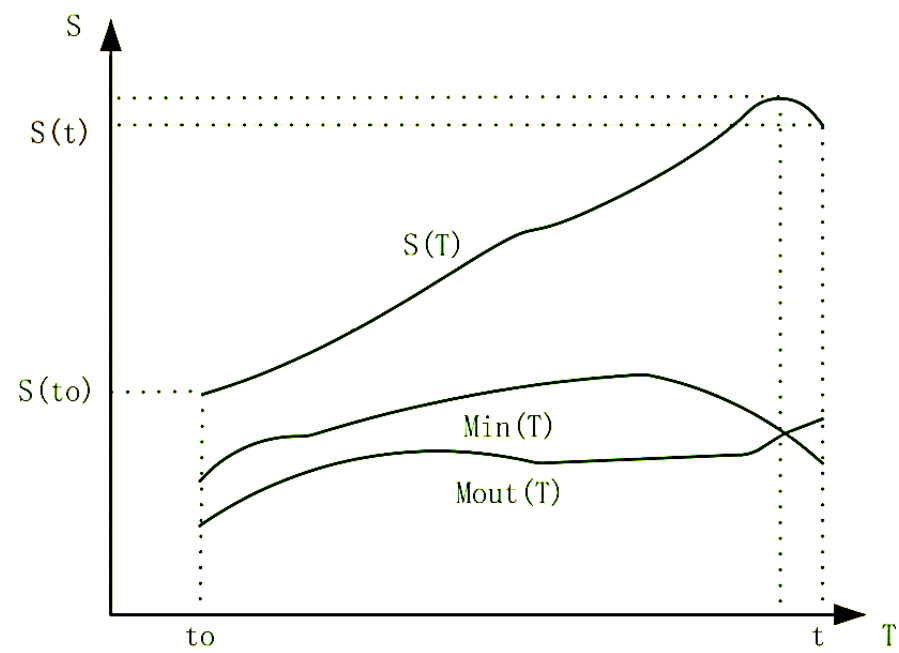

Figure 1. The sketch map of copper in-use stock of the year $t$.

\subsection{Analysis methods of in-use stock}

Stocks result when more copper-containing products enter use than leave use over time. Approaches to estimate stocks are usually classified as "top-down" and "bottom-up". Top-down estimations take information regarding flows and infer stocks by the cumulative difference between inflow and outflow, while bottom-up methods gather information on stock variables to estimate stocks [18].

Top-down method analyses are necessarily conducted on a national scale or larger $[7,15,19]$, for top-down method, if the temporal extent is short or starts in the present, initial stock is defined based on available data or the authors' assumptions [20]. This method is completely dependent on inflow data, because the data of historical outflow are poor to nonexistent, and the required time series of inflow data are often providing by production, trade, or consumption statistics. The top-down method has an advantage in terms of time-series estimation [12]. Bottom-up studies of metal stocks have been performed for various localities [18]. The bottom-up method has an advantage in that it can divide stock into end-uses as detailed as possible. But it is not suitable in estimations for products with big intensity of changes. Bottom-up estimation of stocks of copper scrap directly measures the contents of copper in-use reservoirs and sums them piece by piece. Bottom-up calculation starts by identifying major reservoirs of copper in these categories within a region, the total number of selected products and typical copper content of those products are estimated per category. These data are finally multiplied to find the total copper stock for each category. Most of the reviewed literature applies the top-down approach and others choose the bottom-up approach [20].

Another method to analysis the stock named "average use life method". Which was used to study on the reasons of the excessive growth of steel output in China in 2000; this method was also used to estimate the social stock for metals $\mathrm{Al}$ and $\mathrm{Cu}$ in China [15]. In this paper, this method is also used to analyze the in-use stock of the United States. According to this method, the average use life of copper final products in the year $\mathrm{t}$ is set to $\Delta t$ years. Taking the import and export of copper 
products into considering, disregarding the loss during fabrication and manufacture. The in-use stock of copper $S_{t}$ in the year $t$ showed as equation (2):

\section{Error! Reference source not found.}

where $S_{t}$ is the in-use stock of copper for the year $t$ in the U.S.; Error! Reference source not found. are the values of copper consumption for the year $t,(t-1), \ldots,(t-\Delta t+1)$ respectively.

Compared with the "average use life method", the fixed assets depreciation method is applied to analyze depreciated copper in-use stock [16]. Fixed assets, they are known as tangible assets or property, they comprise many items such as land, buildings, plants, machinery and so on. It used in accounting for assets and property that cannot easily be converted into cash [21,22]. Depreciation is, simply say, the expense generated by the uses of an asset, and it is the wear and tear of an asset or diminution in the historical value owing to usage [16]. As with the "average use life method", the average use life of copper contained products in the year $t$ is set to $\Delta t$, according to the Gaussian distribution; the depreciation span of these products should be $2 \Delta t$. We use the straight-line method (SLM) in this paper, also known as the fixed installment method [22], the annual rate of depreciation is $1 / 2 \Delta t$. So the depreciated copper in-use stock (Error! Reference source not found.) in the year $t$ can be calculated in Equation (3):

\section{Error! Reference source not found.,}

where Error! Reference source not found. represents the depreciated copper in-use stock in the year $t$ of the U.S, and $\mathrm{M}_{t}, \mathrm{M}_{\mathrm{t}-1}, \mathrm{M}_{\mathrm{t}-2}, \mathrm{M}_{\mathrm{t}-2 \Delta t+1}$ are the copper consumption in the year $t,(t-1),(t-2), \ldots$, $(t-2 \Delta t+1)$ respectively.

Copper consumption of a country can be calculated by the following formula:

Error! Reference source not found.

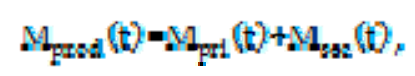

Where the $\mathrm{M}_{\text {con }}(t), \mathrm{M}_{\text {prod }}(t), \mathrm{M}_{\text {impo }}(t), \mathrm{M}_{\mathrm{expo}}(t), \mathrm{M}_{\text {prod }}(t)$ are the consumption, production, imported quantities and exported quantities of copper content in the year $t$; and $\mathrm{M}_{\text {pri }}(t), \mathrm{M}_{\mathrm{sec}}(t)$ represent the primary copper production and the secondary copper production.

\subsection{Data sources}

Consumption is the quantity of refined copper used by the domestic industry (brass mills, wire-rod mills, foundries, etc.), as measured by direct survey of the copper consuming industries, in the production of semi-fabricates, castings, chemicals, etc. in the United States, the data are official figures from the U.S geological survey [32]. In this paper, we simplified the consumption between the year $(t-\Delta t)$ and $t$, constituting the in-use stock in the year $t$. The copper products will be discarded from in-use stock and reclaimed as secondary resources after its lifetime. The data imports (or exports) are the amounts of refined copper imported (or exported) into (from) the United States in various shapes and forms, import data exclude all semi-fabricated and manufactured copper products, primary production means the copper produced from ore, concentrate, or precipitate; secondary production is the copper recovered from old scrap.

Because the quantity of in-use stock derived from the copper consumption previous, to calculated the in-use stock needs large volumes of data before, all the results derived from assumptions in this paper, actually, our consumption data go back to 1925. 
The sources of data for the copper are the mineral statistics publications of the U.S. Bureau of Mines and the U.S. Geological Survey-Minerals Yearbook (MYB) and its predecessor, Mineral Resources of the United States (MR), and Metal Prices in the United States through 1998 (MP98), in this paper it refers to official statistics. The U.S. Geological Survey (USGS) [32], the World Bank database [33]. Some data were directly obtained from statistics in historical records; others were obtained only for a certain year from previous research $[4,7,23,24]$, GDP, and GDP per capita is gross domestic product divided by midyear population. It is calculated without making deductions for depreciation of fabricated assets or for depletion and degradation of natural resources. Data are in constant 2010 prices local currency. In addition to special instructions, the unit used in this paper is Gg.

\section{Results}

\subsection{The quantity of copper in-use stock}

According to the "average use life method", and the Equation (2), (3) and Equation (4), the in-use stock of the U.S during the period 1985-2014 are shown in Figure 2. The depreciation of copper is also considered at the same time. As we can see in the Figure 2, in the period 1985-2000, the in-use stock in the U.S. had increased, after the year 2000, the growth rate of in-use stock is lower than the preceding phases. In the year 2008, the total amount of in-use stock reaches peak, about 70 Mt. From that time, the in-use stock keeps constant and has a slightly decrease. The depreciated copper in-use stock has the same trend as the actual copper in-use stock, but it is little lower than the values of actual copper in-use stock.

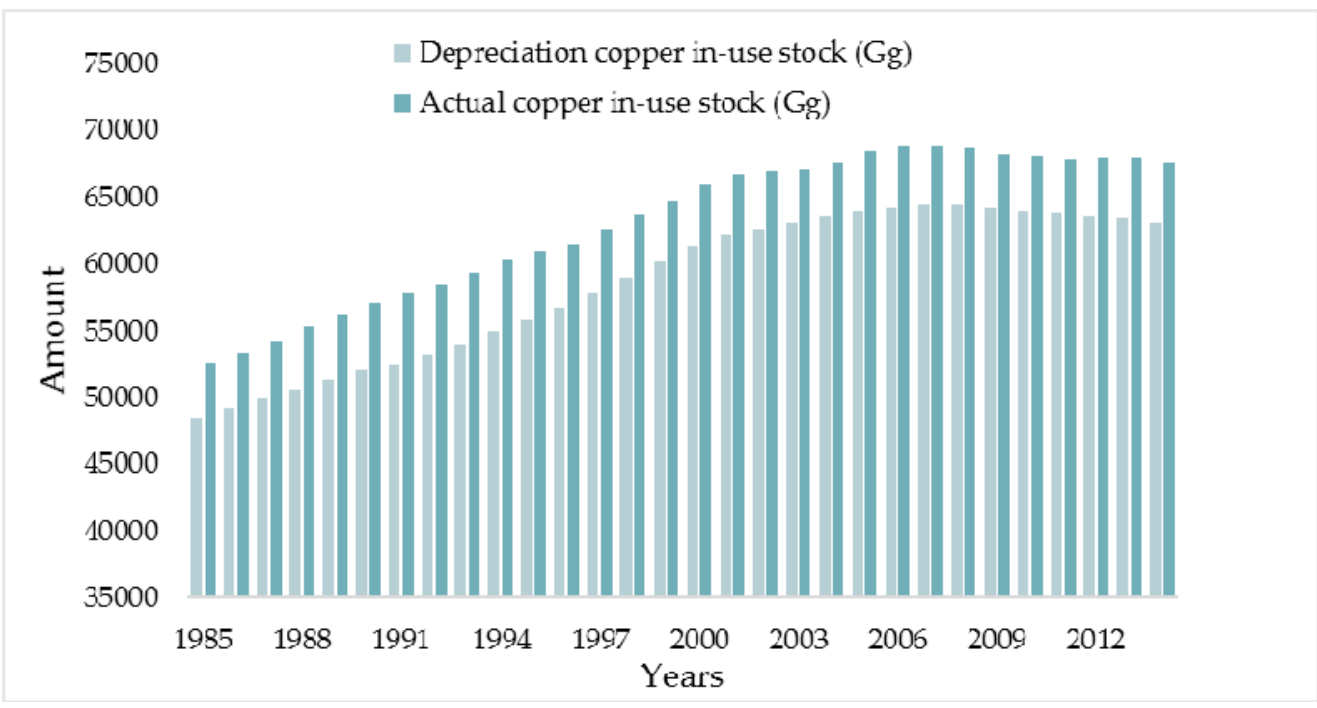

Figure 2. Copper in-use stock in the U.S. during 1985-2014.

The U.S. had the largest copper stocks throughout the entire period, and reached $60 \mathrm{M} t-70 \mathrm{M} t$ of copper stocks in 2010 [25], which is almost equivalent to our estimate. In comparison, Zeltner et al. reported that the copper stock in use in the U.S. was about $70 \mathrm{Mt}$ in 1990 [19], which is greater than our estimate of $57 \mathrm{M} t$ in 1990 and close to the estimated value in 2007 (see Figure 3). Spatari, et al. estimated the in-use reservoirs throughout the 20th century was about $70 \mathrm{M} t$ in North America [7], data assessment demonstrates that $92 \%$ of the total flow of copper in to use in North America entered products used in the U.S. [1], so the in-use stock in the U.S. was about $64.4 \mathrm{Mt}$ of 20th century. The discrepancy might be a result of the use of a longer lifetime for products to estimate stocks. 


\subsection{The average age of copper in-use stock}

Copper products are added to the existing the U.S. in-use stock of copper when they are consumed in the economy. As these new products enter their use phase, others are retired and discarded when they reach the end of their lifetime. They are referred as secondary resources, so estimated the average age of copper in-use stock is important. Copper in-use stock in the year $t$ contains two parts: one is the copper flows into in-use stock in the same year $t$ and another is over a certain number of years before the year $t$, so define the concept of average age for copper products in the in-use stock. Average age of copper products in the in-use stock can be expressed by the Equation (4) [15,16]:

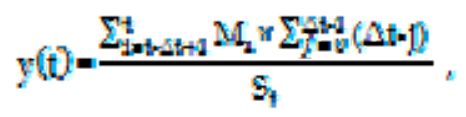

where Error! Reference source not found. is the average age of copper products in the in-use stock, Error! Reference source not found. is copper flows into use in the year $i$. For a definite in-use stock, the older the average age, the larger the reclaimed secondary resources in the short term, in contrast, the younger the average age, the smaller the reclaimed secondary resources.

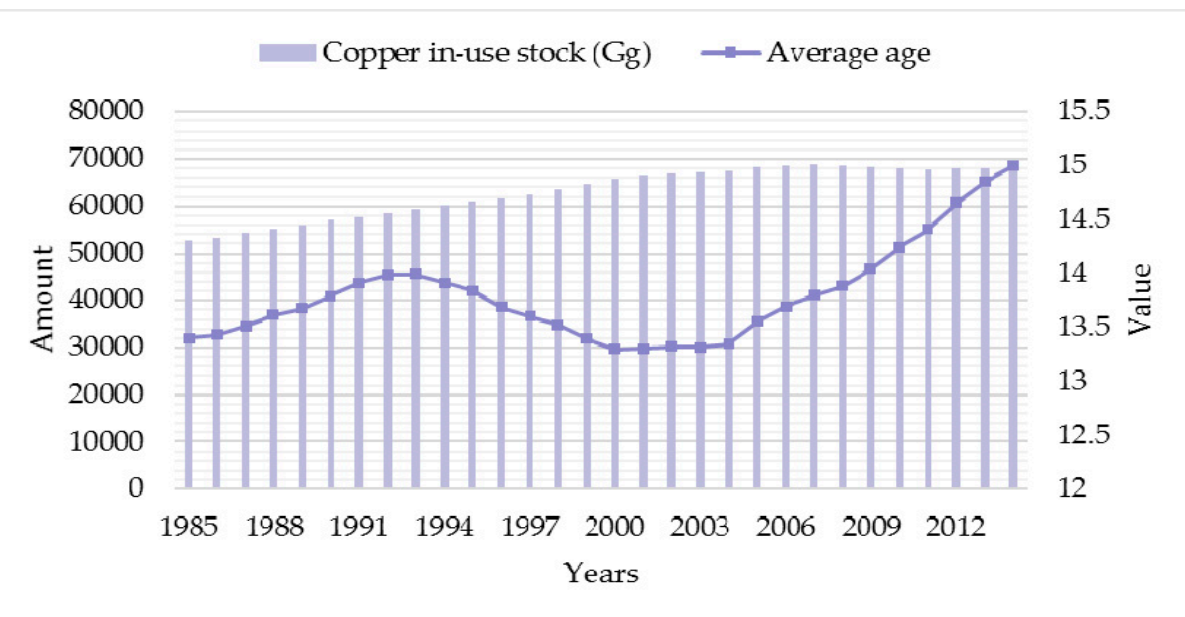

Figure 3. Copper in-use stock and their average age in the U.S. during 1985-2014.

Figure 3 shows the copper in-use stock in the U.S and their average age from 1985-2014. The average age for copper in-use stock between the years 1985-2014 can be calculated according Equation (4) is about 13.8 years. During the period 1985-1992, the average age was increased gradually, from 13.4 years in 1985 to 13.9 years in 1992. Meanwhile, the accumulate in-use stock of refined copper shows a growth. After the year 1992, the average age of copper in-use stock was decreased, the lowest value of the average age was only 13.2 years in the year 2000. From the year 2000 to 2003, the average age was at a steadily numerical value. Since 2004, the average age of copper in-use stock is increase gradually, meanwhile, the amount of copper in-use stock is nearly at its peak, along with the stabilization of copper consumption in the U.S., the average age of copper in-use stock will keep constant or increase gradually.

In comparison, Gl ser has calculated the resulting value for the average age of the current copper stock in-use is about 14 years of the global in-use stock [4], is greater than our estimate before 2008 , and nearly the value in 2009, after 2009, the average age of copper in-use stock is greater than 14 years, the reason is the figure is justified by the continuously increasing global demand, the consumption of copper in developed countries is tend to be stable, but for many developing countries such as China, India, or Brazil, with the development of economy, they need more consumption focused their efforts on building up its physical infrastructure. It is assumed that the United States copper products $(\Delta t)$ to be 30 years. In fact, it is difficult to be determined; these variations are probably due to differences in the average age of in-use stock. 


\subsection{Quantitative analysis of copper in-use stocks and GDP}

The focus of our analysis is the relationship between in-use stock, population, and gross domestic product (GDP). The copper in-use stock in the U.S. during the period 1985-2014 were calculated, based on Equation (2), the relevant data combined with population figures in the U.S. (The world bank database). The GDP during the period 1985-2014, was at the stepped in increases, except for the hiatus in the year 2009. By 1999, the in-use stock had reached $231 \mathrm{~kg}$ of copper per capita, nearly the $238 \mathrm{~kg} /$ person [1]. The in-use stock per capita reached its peak value was about 234 $\mathrm{kg} /$ person, which are in the range of 140-300 $\mathrm{kg}$ per capita reported in 2008 [26]. Before the year 2000, the declining consumption trends lead to stable per-capita copper stocks for the United States. Although the GDP has increased much faster than the copper in-use stock per capita, the rate of per-capita copper stock remains undiminished before 2000.

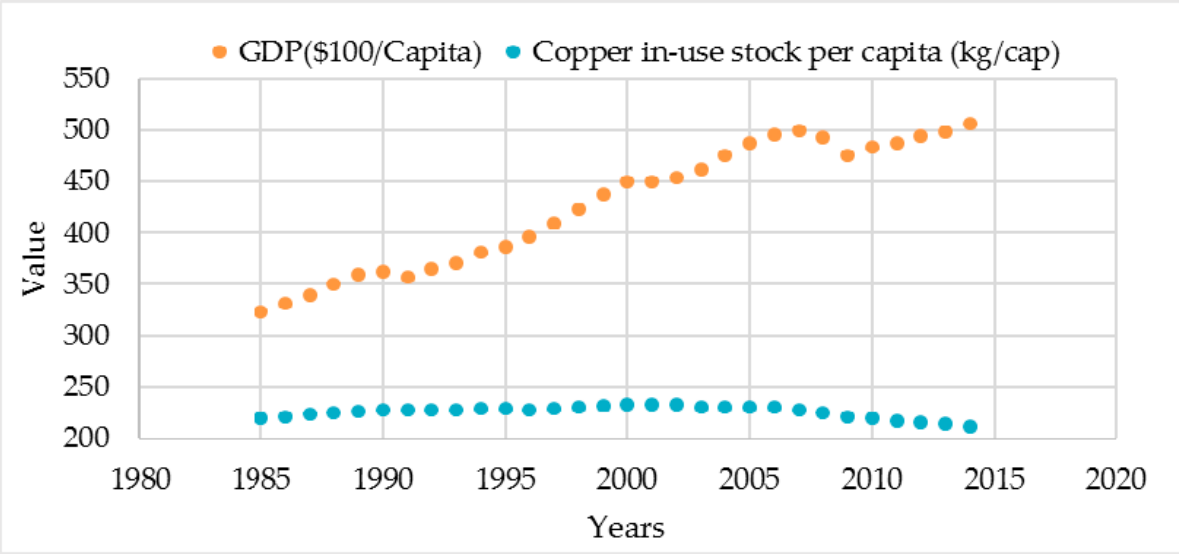

Figure 4. The per-capita copper stock in use in the U.S. and the GDP of the U.S. during 1985-2014.

Developed countries, as the United States, United Kingdom, France, etc., have been completed their industrialization process, and in-use copper quantities have stayed constant [27]. But developing countries, as China, India, etc., are at a stage of the industrial process, which in-use copper stocks show rapid increases and it will take some years before they reach a relatively constant state [16].

Economic predictions are widely available, one popular framework for analyzing metals use in an Environmental Kuznets Curve (EKC) [28,29], which proposed a general relation between a nation's resource use and its GDP, both expressed per capita. But in some studies [30], showed a steady increase in the material input per capita as the GDP per capita increased, in accordance with the U.S. data showed in Figure 4, the reason may be the new and expanded services also required copper, more than offset the reduction in copper intensity achieved by increased efficiency or use of substitutes [1].

\subsection{Analysis of depreciated copper in-use stock}

The depreciated copper in-use stock, and actual copper in-use stock during the period 1985-2014, are depicted in Figure 5. GDP generated per unit depreciated copper in-use stock is showed the use efficiency of copper in-use stock, during the period 1985-2009, it continually increased, except for the year 2010, but since 2010, with in-use stock growth curve down more than the growth in per-capita GDP, the GDP per generated per unit depreciated copper in-use stock increased gradually. 


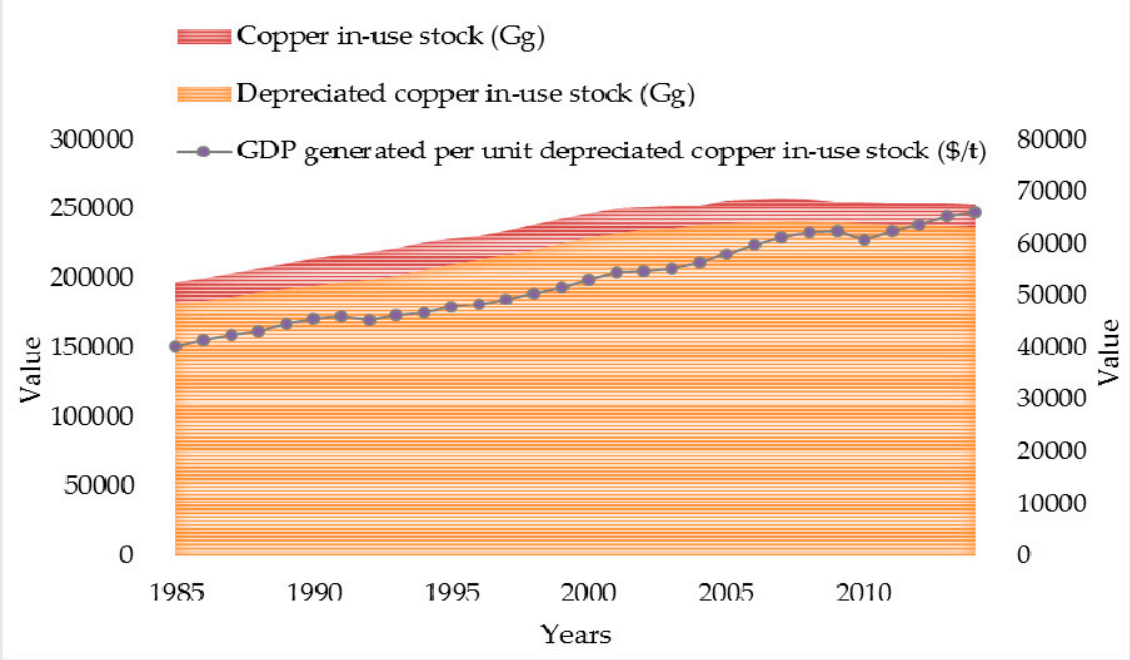

Figure 5. Copper in-use stock, depreciated copper in-use stock and GDP generated per unit copper in-use stock in the U.S. during 1985-2014.

\section{Discussion and Predict}

According to the data on metal consumption of the U.S., UK, Japan in the past one hundred years, metal flow about production and consumption functions can be divided into several types: (1) keeping constant; (2) linear variation; and (3) exponential variation [15,31].

The relevant data in the period 1984-2014 can be obtained from Figure 3 and Figure 4. In the following part of this section, we will discuss the variation of copper consumption on the in-use stock of copper. The average use life of copper products is assumed to be $\Delta t$, and the copper consumption in the initial year is Mo.

In the year 2015, copper consumption keeps almost constant, or has a slight change in recent years. In this paper, (1) constant copper consumption, and (2) linear variation of metal consumption are considered, see Table 1, over the period 2015-2030.

Table 1. Different copper consumption and the average age of in-use stock

\begin{tabular}{|c|c|c|}
\hline & Consumption & Lifetime \\
\hline Model 1 & Constant: $\mathrm{M}_{\mathrm{t}}=\mathrm{M}_{0}$ & $\begin{array}{c}\text { Average } \\
\text { lifetimeError! } \\
\text { Reference source not } \\
\text { found. }\end{array}$ \\
\hline Model 2 & Linear increasing(decreasing): $\mathrm{M}_{\mathrm{t}}=(1+\mathrm{kt}) \mathrm{M}_{0}$ & $\begin{array}{c}\text { Average } \\
\text { lifetimeError! } \\
\text { Reference source not } \\
\text { found. }\end{array}$ \\
\hline
\end{tabular}

Model 1: Constant consumption

Taking the average use life of copper products is 30 years in the U.S., according to the Equation (5), the average age of copper in-use stock can be expressed by following formula:

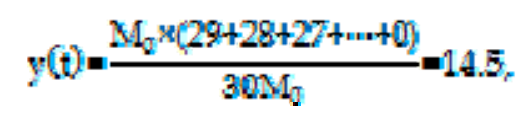


Model 2: Liner variation consumption

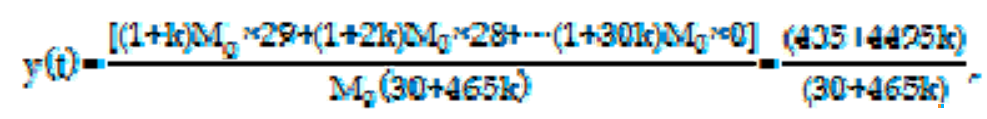

We assume the consumption of copper in the U.S. in 2015 keep constant from 2014 and over the period 2015-2030, the variations of copper in-use stock and average age of in-use stock can be calculated in Figure 6. During 2015-2024, the average age of in-use stock maintaining sustained growth, reaching 16.1 years in 2024. After this period, the average age keeps constant and has a slightly decrease. Meanwhile, the amount of copper in-use stock has a gradual decrement trend, the decrease rate is about $0.7 \%$ per year.

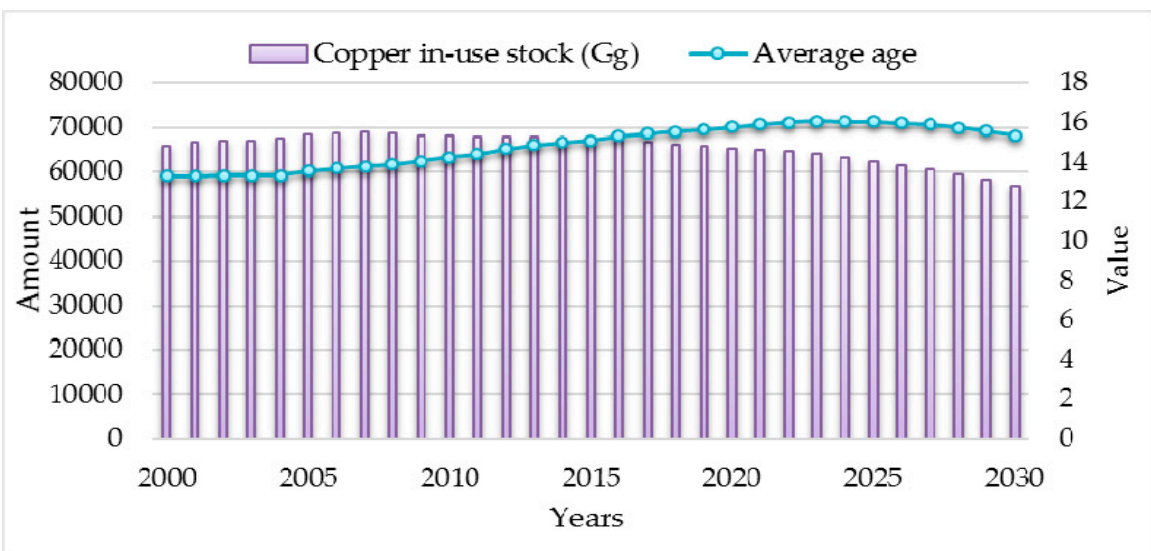

Figure 6. The copper in-use stock and their average age in the period 2000-2030.

Take the change in population numbers, population growth rate was nine over one thousand in nearly a decade, so we assume that the future population growth rate is equal to nine over one thousand over 2015-2030. Combined with the historic data of copper consumption, the copper in-use stock per capita during the period 2015-2030 and the depreciation copper in-use stock also obtained, as depicted in Figure 7 and Figure 8. In this condition, copper in-use stock per capita will decrease in the next decade.

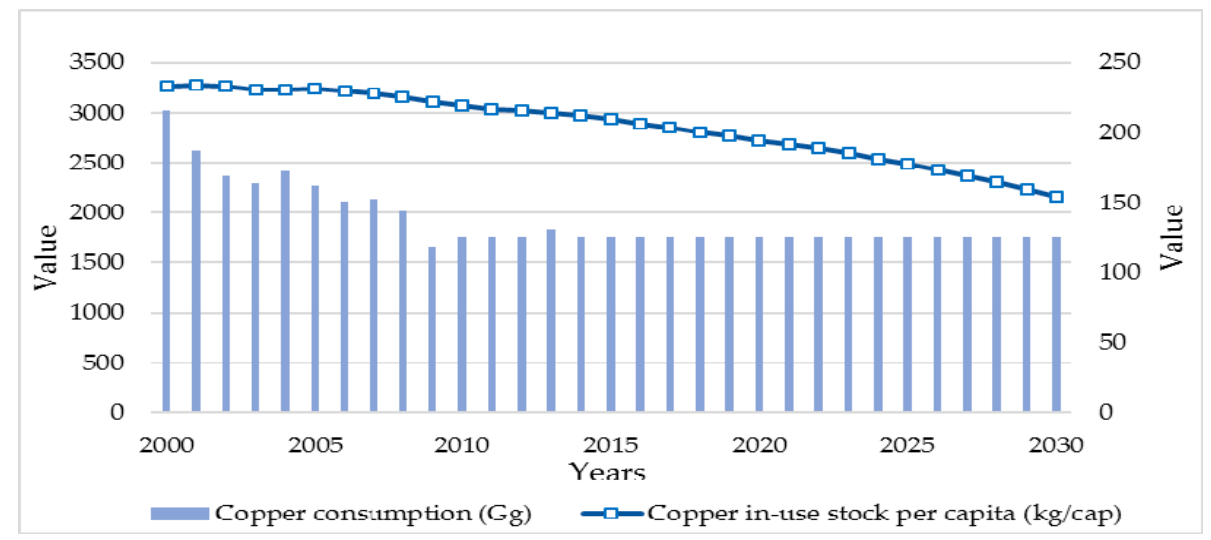

Figure 7. Copper in-use stock per capita and copper consumption during the period 2000-2030.

The copper domestic production was decreased from 2000 in the U.S., but the consumption of copper almost keep stable, this phenomenon may be caused by the refined copper and copper contained products more imports than exports. Because the data of import and export exclude all semi-fabricated and manufactured copper products, so the results may be influenced. Generally speaking, more import copper contained product, the in-use stock per capita will greater than this, instead, more export copper contained products, and the in-use stock per capita will be resulted. 
The U.S. is a net importer of copper semi-fabricated and final products, calculation showed a higher reliance on imports [8]. So the trade of semi-manufactured products may have some influences on the results of copper in-use stock analysis.

In this paper, the copper in-use stock in the United States is analyzed by the average use life method and fixed assets depreciation method. For these two methods, the average use life of copper products should be known, in fact, it is difficult to be determined, because the copper content is different between different end use sectors, such as building and construction, infrastructure, transport, etc. Their use lifetime has considerable difference. The life time of short-term products amounts to approximately 10 years, and the average lifetime of copper in long-term products is assumed to vary between 30 and 70 years [19]. The different assume of the lifespan, the results may be different. If a longer lifetime is selected, the amount of in-use stock may be greater, on the other hand, it will have the opposite result.

\section{Conclusions}

In this paper, based on the assumptions, the quantity of copper in-use stock and their average age during the period 1985-2014 in the U.S. were calculated. Both the average use life method and fixed assets depreciation method were adopted. The average use life method was applied to calculate the quantity of copper in-use stock, per capita in-use stock and the average age of copper in-use stock during the 1985-2014. The Copper consumption of the U.S. had a decrease after the year 2000, the in-use stock had grown since the 1985 and in 2007 the amount of in-use stock reached 68.9 Mt. As for the fixed assets depreciation method, one of advantages is considered the depreciation of copper, and it is more suitable for such analysis that related to economic indicators. The depreciated copper in-use stock had the same trend with the actual in-use stock, but a little lower than it, during the whole period. Average age of in-use stock was increased before 1993, and had a gradual decrement trend during 1994-2001. We also analyzed the relationship between the depreciated copper in-use stock and GDP. The GDP had increased faster than the copper in-use stock, but the in-use stock still keep increase over 1985-2000. GDP generated per unit depreciated copper in-use stock indicated the use efficiency of copper in-use stock. Continually increased since 1985, except for a small fluctuation in 2010. Besides, in the case of the hypothesis, the future 15 years under these scenarios were analyzed. Average age of in-use stock will increase during the period of 2015-2025, and reach 16 years in 2025. With the constant consumption of copper in the next decade, the copper in-use stock per capita will decrease gradually.

As the U.S. is a developed country, it had completed the industrialization at 1980's and into the post-industrial era, the consumption of copper in developed countries is tend to be stable, but for many developing countries such as China, India, or Brazil, with the development of economy, they need more consumption focused their efforts on building up its physical infrastructure, these results also provide some experience for developing the country's future consumption patterns. As time going by and economy developing, the features of copper consumption and stocks in developing countries may be similar to the developed countries like the United States, so the research of this paper is to some extents, can also for developing countries to predict the future copper consumption and take measures to avoid bitterness and possible problems in the future.

\section{Acknowledgments}

This research is supported by funding from Cultivating program of excellent innovation team of Chengdu University of Technology (KYTD201406); Sichuan Social Science Association research base project (SC16E06); The geological surveying project of China Geological Survey (No.121201103000150015); New type management think tanks of Chengdu University of Technology (2017).

\section{Author Contributions}


All authors have made a significant contribution to this research. Minxi Wang and Xin Li conceived and designed the experiments; Yanan Liang collected data and information; Minxi Wang and $\mathrm{Wu}$ Chen provided methods and processed data; Xin Li analyzed the data Yanan Liang wrote the paper.

\section{Conflicts of Interest}

The authors declare no conflict of Internet.

\section{References}

1. Gordon, R.B.; Bertram, M.; Graedel, T.E. Metal stocks and sustainability. Proceedings of the National Academy of Sciences of the United States of America 2006, 103, 1209-1214.

2. Geyer, R.; Davis, J.; Ley, J.; He, J.; Clift, R.; Kwan, A.; Sansom, M.; Jackson, T. Time-dependent material flow analysis of iron and steel in the uk: Part 1: Production and consumption trends 1970-2000. Resources Conservation \& Recycling 2007, 51, 101-117.

3. Ruhrberg, M. Assessing the recycling efficiency of copper from end-of-life products in western europe. Resources Conservation \& Recycling 2006, 48, 141-165.

4. Gloser, S.; Soulier, M.; Tercero Espinoza, L.A. Dynamic analysis of global copper flows. Global stocks, postconsumer material flows, recycling indicators, and uncertainty evaluation. Environ Sci Technol 2013, $47,6564-6572$.

5. Wang, P.-C.; Lee, Y.-M.; Chen, C.-Y. Estimation of resource productivity and efficiency: An extended evaluation of sustainability related to material flow. Sustainability 2014, 6, 6070-6087.

6. H, B.P.; H, R. Pratical handbook of maerial flow analysis. International Journal of Life Cycle Assessment 2004, 9, 337-338.

7. Spatari, S.; Bertram, M.; Gordon, R.B.; Henderson, K.; Graedel, T.E. Twentieth century copper stocks and flows in north america: A dynamic analysis. Ecological Economics 2005, 54, 37-51.

8. Johnson, J.; Graedel, T.E. The "hidden" trade of metals in the united states. Journal of Industrial Ecology 2008, 12, 739-753.

9. Spatari, S.; Bertram, M.; Fuse, K.; Graedel, T.; Rechberger, H. The contemporary european copper cycle: 1 year stocks and flows. Ecological Economics 2002, 42, 27-42.

10. Spatari, S.; Bertram, M.; Fuse, K.; Graedel, T.E.; Shelov, E. The contemporary european zinc cycle: 1-year stocks and flows. Resources, Conservation and Recycling 2003, 39, 137-160.

11. Pauliuk, S.; Wang, T.; Müller, D.B. Steel all over the world: Estimating in-use stocks of iron for 200 countries. Resources, Conservation and Recycling 2013, 71, 22-30.

12. Hirato, T.; Daigo, I.; Matsuno, Y.; Adachi, Y. In-use stock of steel estimated by top-down approach and bottom-up approach. Isij International 2009, 49, 1967-1971.

13. McMillan, C.A.; Moore, M.R.; Keoleian, G.A.; Bulkley, J.W. Quantifying u.S. Aluminum in-use stocks and their relationship with economic output. Ecological Economics 2010, 69, 2606-2613.

14. Liu, G.; Muller, D.B. Centennial evolution of aluminum in-use stocks on our aluminized planet. Environ Sci Technol 2013, 47, 4882-4888.

15. Yue, Q.; Wang, H.-m.; Lu, Z.-w. Quantitative estimation of social stock for metals al and cu in china. Transactions of Nonferrous Metals Society of China 2012, 22, 1744-1752.

16. Yue, Q.; Wang, H.; Gao, C.; Du, T.; Li, M.; Lu, Z. Analysis of iron in-use stocks in china. Resources Policy 2016, 49, 315-322.

17. Bonnin, M.; Azzaro-Pantel, C.; Pibouleau, L.; Domenech, S.; Villeneuve, J. Development and validation of a dynamic material flow analysis model for french copper cycle. Chemical Engineering Research and Design 2013, 91, 1390-1402.

18. Zhang, L.; Yuan, Z.; Bi, J. Estimation of copper in-use stocks in nanjing, china. Journal of Industrial Ecology 2012, 16, 191-202.

19. Zeltner, C.; Bader, H.P.; Scheidegger, R.; Baccini, P. Sustainable metal management exemplified by copper in the USA. Regional Environmental Change 1999, 1, 31-46.

20. Muller, E.; Hilty, L.M.; Widmer, R.; Schluep, M.; Faulstich, M. Modeling metal stocks and flows: A review of dynamic material flow analysis methods. Environ Sci Technol 2014, 48, 2102-2113.

21. Albonico, A.; Kalyvitis, S.; Pappa, E. Capital maintenance and depreciation over the business cycle. 
Journal of Economic Dynamics \& Control 2013, 39, 273-286.

22. Liapis, K.J.; Kantianis, D.D. Depreciation methods and life-cycle costing (lcc) methodology. Procedia Economics and Finance 2015, 19, 314-324.

23. Graedel, T.E.; Bertram, M.; Reck, B. Exploratory data analysis of the multilevel anthropogenic zinc cycle. Journal of Industrial Ecology 2005, 9, 91-108.

24. Graedel, T.E.; Van Beers, D.; Bertram, M.; Fuse, K.; Gordon, R.B.; Gritsinin, A.; Kapur, A.; Klee, R.J. Multilevel cycle of anthropogenic copper. Environmental Science E Technology 2004, 38, 1242-1252.

25. Maung, K.N.; Hashimoto, S.; Mizukami, M.; Morozumi, M.; Lwin, C.M. Assessment of the secondary copper reserves of nations. Environ Sci Technol 2017, 51, 3824-3832.

26. Gerst, M.D.; Graedel, T.E. In-use stocks of metals: Status and implications. Environmental Science $\mathcal{E}$ Technology 2008, 42, 7038-7045.

27. Mueller, D.B.; Wang, T.; Duval, B. Patterns of iron use in societal evolution. Environmental Science $\mathcal{E}$ Technology 2011, 45, 182-188.

28. Selden, T.M.; Song, D. Neoclassical growth, the $\mathrm{j}$ curve for abatement, and the inverted $\mathrm{u}$ curve for pollution. Journal of Environmental Economics and Management 1995, 29, 162-168.

29. Grossman, G.M.; Krueger, A.B. Economic growth and the environment. Review of Economic Studies 1995, 110, 353-377.

30. Bringezu, S.; Schütz, H.; Steger, S.; Baudisch, J. International comparison of resource use and its relation to economic growth : The development of total material requirement, direct material inputs and hidden flows and the structure of tmr. Ecological Economics 2004, 51, 97-124.

31. Kleijn, R.; Huele, R.; van der Voet, E. Dynamic substance flow analysis: The delaying mechanism of stocks, with the case of pvc in sweden. Ecological Economics 2000, 32, 241-254.

32. U.S Geological Survey: Copper Statistics and Information. 2017 Available online: https://minerals.usgs.gov/minerals/pubs/commodity/copper/ (assessed on 12 May 2017).

33. World Bank national accounts data, and OECD National Accounts data files. 2017 Available online: http://data.worldbank.org/indicator/ (assessed on 13 May 2017). 